\title{
In vitro assays of Phytophthora agathidicida on kauri leaves suggest variability in pathogen virulence and host response
}

\author{
Echo M. Herewini ${ }^{1,2}$, Peter M. Scott ${ }^{2}$, Nari M. Williams² and Rosie E. Bradshaw ${ }^{1, \star}$ \\ ${ }^{1}$ Bio-Protection Research Centre, Institute of Fundamental Sciences, Massey University, \\ Palmerston North 4442, New Zealand \\ ${ }^{2}$ Scion (New Zealand Forest Research Institute, Ltd.), 49 Sala Street, Rotorua 3046, New \\ Zealand \\ *Corresponding author: r.e.bradshaw@massey.ac.nz
}

\begin{abstract}
Phytophthora agathidicida is an aggressive soil-borne oomycete pathogen that kills New Zealand kauri trees (Agathis australis). When artificially inoculated, P. agathidicida causes lesions on leaves as well as roots, providing a non-invasive method for virulence screening. However, little is known about the extents to which the pathogen varies in virulence and kauri trees vary in disease susceptibility. Three isolates of $P$. agathidicida grown in culture were inoculated onto detached leaves from six kauri trees. Visible disease lesions were measured and the extent of asymptomatic leaf colonisation determined by culturing. All six trees were susceptible to $P$. agathidicida, but one showed higher susceptibility than the others. The pathogen also showed variability in virulence among isolates. Asymptomatic colonisation of leaf tissue was also found, suggesting a latent or biotrophic phase for the pathogen. Although further work is needed, the variability of both pathogen virulence and host susceptibility have important implications for management of kauri dieback. Furthermore, asymptomatic colonisation of kauri tissues suggests that $P$. agathidicida could be present outside of regions with visible disease symptoms.
\end{abstract}

Keywords Phytophthora, kauri, asymptomatic infection, kauri dieback.

\section{INTRODUCTION}

The iconic New Zealand kauri is under serious threat from the soil-borne kauri dieback pathogen, Phytophthora agathidicida (Weir et al. 2015). This destructive pathogen can kill all life stages of kauri and has been identified throughout the upper North Island of New Zealand, where kauri naturally occur (Waipara et al. 2013). Symptoms of infection include aggressive root and collar rot, canopy thinning, yellowing of foliage, bleeding resins at the base of the trunk and tree mortality (Beever et al. 2009).

A screening assay that can rapidly identify resistant kauri trees would provide an effective management tool for this disease. Phytophthora agathidicida naturally infects roots but detached leaves may be a good alternative source of material to test that is non-destructive and could accelerate the screening process. Leaves are also commonly used as bait material for these pathogens, providing a scalable and rapid means of initial compatibility testing (Tahi et al. 2006). This approach has been used in screening with other species of Phytophthora (Hüberli et al. 2008; Ireland et al. 2012) and successfully integrated in breeding and screening for Phytophthora spp. resistance (Tahi et al. 2006).

Kauri live for hundreds of years with the oldest living specimens estimated to be more than 1500 years old. With direct inoculation of these iconic 
trees not being an option, a non-invasive means of determining the susceptibility of established trees would be advantageous. Foliar inoculations with two $P$. agathidicida isolates were previously conducted on glasshouse-grown two-year-old kauri (Horner \& Hough 2014) but have yet to be conducted on older forest-grown kauri that may differ in disease tolerance. The current study focused on whether three different isolates of $P$. agathidicida vary in virulence and whether kauri trees aged 7-8 years vary in disease susceptibility. Using a wounded detached foliar assay, we also investigated whether this pathogen is present in asymptomatic tissue in advance of visible disease lesions.

\section{MATERIALS AND METHODS}

Phytophthora agathidicida isolates and kauri trees The $P$. agathidicida isolates used were from the Scion collection and had been baited from kauri rhizosphere soil in the Coromandel (NZFS 3813 and NZFS 3814), or the Waitākere ranges (NZFS 3118). They were grown in carrot agar (CA): $200 \mathrm{~g}$ minced frozen carrots, mixed with $15 \mathrm{~g}$ agar (BBLTM Grade A, BD Life Sciences) per litre. Six kauri saplings (T1-T6), 7-8 years in age, from the Scion Long Mile Reserve (Long Mile Rd., Rotorua) were used. These were second-generation saplings propagated in 2007/2008 from seed from Holt's Forest (Hawke's Bay) kauri that were originally planted in the 1980s from seed from the Waipoua grafted nursery. All lines were open pollinated seed from bulk collections, with details of the maternal parents not recorded. The trees were selected to represent a diverse range of foliar and structural phenotypes.

\section{Leaf assays and statistical analysis}

Forty leaves were collected from each kauri tree and placed abaxial side up on wet paper towels in a plastic tray. In a randomised split-plot design, ten leaves were inoculated with each $P$. agathidicida isolate by placing a colonised CA plug over a small surface needle wound at the base of the leaf, or with an uncolonised CA plug as a control. The trays were sealed with plastic film and incubated for 6 days in a controlled atmosphere at $20-23^{\circ} \mathrm{C}$ and with $12 \mathrm{~h}$ light $/ 12 \mathrm{~h}$ dark. The distance of lesion spread from the inoculation point was measured. To determine the extent of pathogen growth beyond the disease lesion, four 5-mm segments of leaf (see Fig. 1) were plated onto CRNH medium (Jeffers \& Martin 1986) and incubated for 6 days at $20^{\circ} \mathrm{C}$. Colony growth was checked every 2 days and the identity of $P$. agathidicida colonies confirmed microscopically (Weir et al. 2015). The data shown in Table 1 were log-transformed to satisfy assumptions of normal distribution and homogeneity of variance for ANOVA, followed by Tukey's multiple comparisons test, using GraphPad Prism 7 software.

\section{RESULTS}

Mean disease lesion lengths (Table 1) were calculated for each tree and isolate to determine differences in pathogen virulence and host response to infection by $P$. agathidicida. None of the uninoculated controls showed lesions.

A two-way ANOVA showed significant differences between trees $(\mathrm{P}<0.0001)$ and between pathogen isolates $(\mathrm{P}<0.0001)$ but no significant interaction. Tukey's multiple comparisons test showed Tree T4 had significantly larger lesions than all other trees $(\mathrm{P}<0.0002$ in all pairwise comparisons) and significant differences between pathogens (3118 significantly different to both 3813 and 3814 with $\mathrm{P}<0.0001$ ).

Phytophthora agathidicida was recovered from asymptomatic leaf tissue beyond the visible disease lesion (Fig. 1). On average, the pathogen was found $7.42 \mathrm{~mm}$ ahead of the visible lesion. Given the 6-day observation period and lesion growth rate of $3.03 \mathrm{~mm} /$ day, this indicates a direct latency between infection and visible lesion development of 2.5 days, but this varied with tree and pathogen isolate. The mean extent of growth beyond the lesion margin was significantly different among trees $(\mathrm{P}<0.0001)$, with T4 hosting more asymptomatic growth than the others. However, there were only marginal differences among pathogen isolates $(\mathrm{P}=0.038) ; 3118$ had shorter mean asymptomatic lesion length $(6.3 \pm$ $2.0 \mathrm{~mm})$ than $3813(8.0 \pm 2.4 \mathrm{~mm})$ and $3814(8.0$ $\pm 1.7 \mathrm{~mm}$ ). 
Table 1 Mean visible disease lesion length by isolate and tree for leaves collected from six kauri trees (T1-T6) inoculated with three $P$. agathidicida isolates (NZFS).

\begin{tabular}{llccc}
\hline & \multicolumn{4}{c}{ Disease lesion length $(\mathrm{mm})$ Mean \pm SD $(\mathrm{n}=10)$} \\
Tree (T) & NZFS 3813 & NZFS 3814 & NZFS 3118 & Tree Means $^{1}$ \\
\hline T1 & $19.5 \pm 6.9$ & $14.9 \pm 5.0$ & $10.7 \pm 3.4$ & $15.0 \pm 4.4^{\mathrm{a}}$ \\
T2 & $19.8 \pm 3.7$ & $18.3 \pm 2.9$ & $9.9 \pm 3.0$ & $16.0 \pm 5.3^{\mathrm{a}}$ \\
T3 & $22.5 \pm 3.0$ & $17.3 \pm 6.5$ & $10.1 \pm 2.9$ & $16.6 \pm 6.3^{\mathrm{a}}$ \\
T4 & $33.2 \pm 4.1$ & $28.4 \pm 4.0$ & $24.5 \pm 10.5$ & $28.7 \pm 4.3^{\mathrm{b}}$ \\
T5 & $20.6 \pm 3.5$ & $19.1 \pm 2.1$ & $10.4 \pm 4.2$ & $16.7 \pm 5.5^{\mathrm{a}}$ \\
T6 & $20.3 \pm 3.4$ & $18.8 \pm 8.2$ & $9.5 \pm 4.3$ & $16.1 \pm 5.9^{\mathrm{a}}$ \\
\hline Path. Means $^{1}$ & $22.6 \pm 5.3^{\mathrm{a}}$ & $19.4 \pm 4.6^{\mathrm{a}}$ & $12.5 \pm 5.9^{\mathrm{b}}$ & \\
\hline
\end{tabular}

${ }^{1}$ Different letters between means within row or column indicate significant differences.

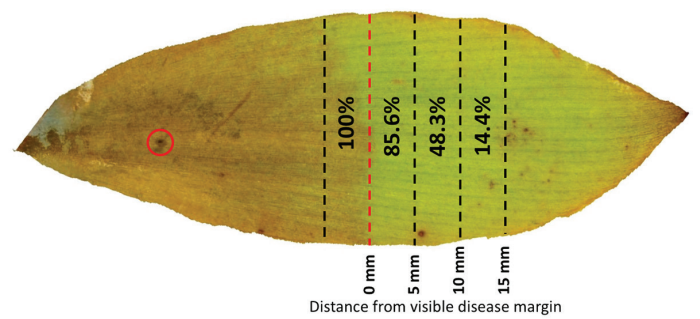

Figure 1 Recovery of Phytophthora agathidicida from asymptomatic leaf tissue. The inoculation point (red circle) and visible disease front (red line) are indicated. Percentages of all inoculated leaf samples $(\mathrm{n}=180)$ are shown from which $P$. agathidicida was recovered by plating leaf tissue segments from up to 5, 10 and $15 \mathrm{~mm}$ ahead of the lesion front.

\section{DISCUSSION}

This study provided evidence for differences in pathogen virulence and host response to infection by $P$. agathidicida. Asymptomatic growth ahead of the lesion front further suggests a biotrophic or latent stage in leaf tissue which is common for Phytophthora pathogens on compatible hosts. This phase provides an opportunity for the pathogen to develop persistent structures ahead of necrotrophic responses by the host (Crone 2012). It is likely that a similar latent period would be observed during root infection, although this was not investigated here. Our work does, however, highlight the importance of considering latency when assessing host susceptibility. Complete resistance has not yet been observed in kauri inoculated with $P$. agathidicida so the ability for the host to mount a rapid response that minimises the extent of unimpeded biotrophic infection may be a key factor in host resistance.

This study confirmed earlier findings (Horner \& Hough 2014) that leaves can be used in screening kauri for susceptibility to kauri dieback, although those authors did not report differences in lesion advance between the two isolates they tested. However, variation among isolates was observed in the current study, which suggests possible differences in virulence. Variation was also observed among trees, which may relate to the susceptibility of the tree as a whole. However, because this was done as a screening assay for a disease that impacts the root and collar of the tree, it can only be taken as an initial screen for true susceptibility. Future studies should apply this approach across replicate clonal trees and/ or families of kauri with parallel comparisons to root-inoculation studies, to determine if results from leaf and root inoculations are comparable. A kauri-leaf assay could also be used to test the efficacy of products such as elicitors, which could be applied to the trees and then leaves bio-assayed to determine if host defences were induced that help to protect against infection. Our work also suggests that detached kauri leaves can be infected 
by $P$. agathidicida and may present an alternate source of host material in which the pathogen can persist in the forest.

\section{ACKNOWLEDGEMENTS}

This work was funded by the Bio-Protection Research Centre in partnership with the Healthy Trees, Healthy Future programme (MBIE C04X1305). The authors thank Scion technical staff for their help with laboratory work and maintenance of kauri plants, in particular Keiko Gough, Catherine Banham, Pam Taylor and Greg Steward, as well as Stan Bellgard for his feedback and discussion.

\section{REFERENCES}

Beever RE, Waipara N, Ramsfield, TD, Dick MA, Horner IJ 2009. Kauri (Agathis australis) under threat from Phytophthora? Phytophthoras in Forests and Natural Ecosystems; Fourth Meeting of the International Union of Forest Research Organizations (IUFRO) Working Party S07.02.09, Monterey, California, USA.

Crone M 2012. Persistence of Phytophthora cinnamomi in nature: Biotrophic growth and presence of stromata, oospores and chlamydospores in annual and herbaceous perennial plant species. PhD thesis, Murdoch University.

Horner IJ, Hough EG 2014. Pathogenicity of four Phytophthora species on kauri: in vitro and glasshouse trials. New Zealand Plant Protection 67: 54-59.
Hüberli D, Lutzy B, Voss B, Calver M, Ormsby M, Garbelotto M 2008. Susceptibility of New Zealand flora to Phytophthora ramorum and pathogen sporulation potential: an approach based on the precautionary principle. Australasian Plant Pathology 37: 615-625.

Ireland KB, Hüberli D, Dell B, Smith IW, Rizzo DM, Hardy G 2012. Potential susceptibility of Australian native plant species to branch dieback and bole canker diseases caused by Phytophthora ramorum. Plant Pathology 61: 234-246.

Jeffers S, Martin S 1986. Comparison of two media selective for Phytophthora and Pythium species. Plant Disease 70: 1038-1043.

Tahi GM, Kébé BI, N'Goran JAK, Sangaré A, Mondeil F, Cilas C, Eskes AB 2006. Expected selection efficiency for resistance to cacao pod rot (Phytophthora palmivora) comparing leaf disc inoculations with field observations. Euphytica 149: 35-44.

Waipara NW, Hill S, Hill LMW, Hough EG, Horner IJ 2013. Surveillance methods to determine tree health, distribution of kauri dieback disease and associated pathogens. New Zealand Plant Protection 66: 235-241.

Weir BS, Paderes EP, Anand N, Uchida JY, Pennycook SR, Bellgard SE, Beever RE 2015. A taxonomic revision of Phytophthora Clade 5 including two new species, Phytophthora agathidicida and P. cocois. Phytotaxa 205: 2138 . 